\title{
Present Status and Conservation of Sri Lankan Aponogeton
}

\author{
Manawaduge C.G. and Yakandawala D.M.D.* \\ Department of Botany, University of Peradeniya, Sri Lanka \\ *deepthiyakandawala@gmail.com
}

\begin{abstract}
Aponogeton is an aquatic genus, represented by four species in Sri Lanka, listed under various conservation categories in The National Red List, A. jacobsenii (CR), A. rigidifolius (EN), A. crispus (VU) and A. natans (VU), of which the former two are endemic. A study on the occurrence and the distribution of Sri Lankan Aponogeton was carried out during the past two years. According to records, A. jacobsenii has been commonly occurring in central highlands. However, during this study, other than the luxurious population in Horton Plains National Park, we could encounter only few, very small poorly grown populations in Pattipola area, which might disappear in near future due to lack of water and the invasion of rushes. Even though, according to literature, A. rigidifolius has commonly occurred in Kaluthara, Rathnapura and Galle districts of the wet zone, we were unable to find any populations in Kaluthara, instead a new undescribed Aponogeton species superficially resembling A. rigidifolius, growing luxuriously. Nevertheless, other few populations encountered in Ratnapura and Galle districts, are under threat due to various anthropogenic activities. Further, despite of being in a protected area, the population beside the entrance of the Kanneliya Forest Reserve has declined considerably within past two years. As in literature, even though, A. natans has been distributed throughout the dry zone and considered as the most common species, we encountered only few populations. Moreover, its habitats; shallow stagnant waters, rice fields and marshes are now disappearing due to the constructions and climate changes, causing a severe threat for its existence. On the other hand, even though there is an apparent reduction, A. crispus is the most abundant species and has shown a satisfactory distribution in the dry and intermediate zones but could be under threat due to the habitat destructions. In addition, these species are extracted in large scale for consumption and medicinal purposes causing sever threat, especially for the two endemics. Contemporary observations have revealed that there is a high possibility of some Aponogeton spp. being extinct from wild in the future. Thus it is necessary to take relevant sustainable measures to conserve these plants and upgrading the conservation status of $A$. rigidifolius and $A$. natans is recommended.
\end{abstract}

Keywords: Aquatic plants, Ornamental aquatics, Conservation status, Threaten species, Over exploitation

Proceedings of the International Forestry and Environment Symposium 2016, Department of Forestry and Environmental Science, University of Sri Jayewardenepura, Sri Lanka. 